\title{
Identification of unclaimed dead bodies- A possible aadhar based solution
}

\author{
Arvind Kumar ${ }^{1}$, Mahesh Kumar ${ }^{2 *}$, Rishabh Kumar Singh ${ }^{3}$ \\ ${ }^{1}$ Professor, ${ }^{2}$ Assistant Professor, ${ }^{3}$ Senior Resident, ${ }^{2}$ Dept. of Forensic Medicine and Toxicology Indira Gandhi Medical \\ College Shimla, Himachal Pradesh, ${ }^{1,3}$ Dept. of Forensic Medicine and Toxicology Lady Hardinge Medical College
} New Delhi India

*Corresponding Author:

Email: mahesh25881@gmail.com

\begin{abstract}
Establishing the identity is the first step in any investigation process. Without this it is very difficult to proceed with the inquiry. It is said that the dead speaks but we should be having ears for hearing; meaning we should be properly equipped and oriented to make use of all the available resources for the same. The conventional methods followed in our country leaves many lacunae in the process of identification and therefore many a times the dead body remains unidentified. It increases the burden of unsolved crimes and the accused can easily get away if the identity of the victim is not established. Moreover it further dents the hopes of grieving relatives. So it becomes more important to use the best of our available resources to fasten the process of identification and make it more efficacious. One such method that can be used is AADHAAR by UIDAI. Making use of it will not only fasten the process of identification but also make it more efficacious and accurate.
\end{abstract}

Keywords: Identification, ZIPNET, Facts, Aadhar, STQC, CCTN.

\section{Introduction}

Despite having registered Aadhar data for $89.2 \%$ of Indian population, problem of identification after death remains a chalange. ${ }^{1}$ A large number of missing reports are lodged in police stations of the National capital every day. Also, many of the dead bodies are recovered with no identification card/mark/proof found on them. It is very important to make sincere and systematic efforts to trace out the missing persons and identify the unidentified dead bodies. The overwhelming desire of relatives (from all religions and cultures) is to identify their loved ones. All efforts to identify the bodies will help. The efforts for identification remains disproportionate, the apathy towards unknown dead bodies can be felt through following expression;

"A case of unknown

Should somebody touch and try

And listen to the silence of Hue and cry?

Even the investigations are not taken up with moral so high.

Cold room is getting up hot and dry

Even "72 hours" soon will fly.

Should, only keeping a piece of bone considered as so high?

Or certified cause of death should be notified?

Who is bothered, who and why an unknown have died?"

Grieving and traditional individual burial (or other means of disposal of the body) are important factors for the personal and communal recovery or healing process. Identification of unclaimed dead bodies would also significantly reduce the burden of unsolved crimes in a society. This paper highlights the existing practices followed by police to trace the unidentified dead bodies, the lacunae thereof and the future solutions by use of existing IT framework i.e. Aadhar, for the problems encountered during identification process.

Current practice followed by Delhi Police while dealing with unidentified dead bodies: As per The Revised Standing Order of Delhi police, in the event of recovery of an unidentified dead body, the following steps will be taken by the Investigating Officer:

1. A D.D. entry should be lodged at the Police Station or Police Post as soon as the information is received and the SHO/ACP be informed immediately.

2. The scene of crime shall be visited by the $\mathrm{SHO} / \mathrm{ACP}$.

3. The dead body will be photographed form different angles. Care should be taken to ensure that the face and identifying marks are captured clearly in the photographs. Photographs must be of high-quality taken on a superior quality digital camera. Where possible, services of a private photographer be engaged so that high-quality photographs are taken which are lucid and clear when transmitted by computer etc.

4. The dead body will be sent for autopsy to ascertain to cause of death, duration since death, age etc. and if needed, Doctor/Medico Expert report be requested to preserve limb of the deceased for DNA purposes.

5. The search slip of the deceased will be prepared and sent to the Finger Print Bureau to ascertain the identity of the deceased from records of FPB. Even if the skin is contracted or wrinkled due to decomposition, the search slip should be prepared and the doctor be requested to remove the skin. All the 10 digits should be sent to the Finger Print Bureau. 
6. The unidentified dead body shall be preserved for at least 72 hours in the mortuary and all efforts will be made to get it identified.

7. Wireless Messages shall be flashed to all SHOs, ACP and DCP in Delhi and to all district SSP in India

8. Enquiries will be made at the place of recovery of the unidentified dead body regarding the circumstances under which the body was recovered.

9. Hue \& Cry notices with the photograph of the deceased will be distributed.

10. Wide publicity should be given through the Electronic and Print Media. SCRB (State Crime Record Bureau) and NCRB (National Crime Record Bureau) shall also be informed about the recovery of UIDB (Unique Identification Authority of India).

11. The clothes, ornaments and other articles found on the deceased shall be preserved. Any birth mark, scar, tattoo mark, Dhobi/Tailor Mark on clothing, deformity on the body etc. shall be clearly recorded.

12. All the articles found on the body and around shall be taken into possession as pieces of evidence.

13. In cases of hanging, the mode and the height of point of suspension shall be clearly recorded. Opinion of autopsy doctor on the load bearing capacity of rope/cloth etc. use for hanging be sought. Also the autopsy surgeon be asked to asked to opine on the correspondence between the ligature mark and the ligature used.

14. In cases of drowning, the depth of water and presence of nay foreign matter sticking to the body shall be mentioned. Autopsy surgeon's opinion be sought whether the drowning is forces, accidental or suicidal.

15. In cases of poisoning, search for the container shall be made. Vomited material stool, nails hair etc. shall also be preserved and sent for foreign analysis.

16. The District Missing Persons (DMPU) /Missing Persons Squad (MPS) shall be informed to check if any person of similar description is missing from any other police station. If so, his/her relatives/acquaintances should be informed.

17. If the body bears injuries, the autopsy surgeon will be requested to opine on the following:-

a) The nature of injuries i.e. ante-mortem or postmortem and whether sufficient to cause death.

b) Whether the injuries are homicidal, suicidal or accidental c) Whether the injuries are selfinflicted or otherwise.

c) Other queries can be added as per requirement in the investigation of the case.

18. Keeping in view the autopsy report and the circumstances of the case, the ACP, SHO and I.O. should examine whether it is a case of homicidal, suicidal, accidental or natural death.

19. If it is a case of cognizable crime, a case should be registered forthwith under the appropriate sections of law and taken up for investigation.

20. If the deceased is identified, his/her relatives and acquaintances shall be contacted to find out the possible reasons for the death.

21. A separate register of unidentified dead bodies shall be maintained at each Police-Station. The SHOs and ACP shall scrutinize this register frequently and ensure that all requisite steps to identify the body have been taken. Whenever required, they shall initiate further legal action as per circumstances of the case. ${ }^{2}$

\section{Lacunae in the existing practice}

1. The photographs circulated through hue and cry notice printed in newspapers are generally of poor quality.

2. The biological samples preserved for DNA fingerprinting are generally kept in Maalkhana of the police station which has no facility for preservation of biological samples.

3. There is no guidelines for specification for the photographs (like front view/close up/shadow less/ different view/ picture quality etc.) which is to be uploaded on ZIPNET $^{3}$ (Zonal Integrated Police Network which is a real time plateform for sharing of crime and criminal information among eight member states (Delhi, Haryana, UP, Rajasthan, Punjab, Chandigarh and Himachal Pradesh). Currently it has a record of 70105 un-identified dead bodies. There is no linkage of data of missing person with the data of unidentified dead bodies on ZIPNET. Delhi being the capital and metropolitan city, inward flow of people from all over the country is seamless. Therefore the existing ZIPNET with only eight member states poses considerable limitations on the identification of criminals from other non-member states.

4. Central finger print bureau (CFPB) only maintains a database of fingerprint of criminals which uses Facts $^{4}$ (Fingerprint Analysis and Criminal Tracking System) which is an advanced finger print identification system. The search slip of the deceased is prepared and sent to the Finger Print Bureau to ascertain the identity of the deceased from records of CFPB. However the fingerprint of unclaimed bodies (which may not be criminals) do not find it's place in the main database/repository as this database comprise of only records of criminal.

5. The fingerprints of unclaimed dead bodies taken by police at mortuary before the post-mortem are usually of poor quality which is ink pad based. These poor quality fingerprints have their own drawbacks like non-reproducibility and they are prone to distortion over a period of time. 
6. CCTNS $^{5}$ (Crime and Criminal Tracking Network and Systems) is a mission mode project under the National e-Governance plan of Govt of India. It is a nationwide networking infrastructure used for tracking of investigation of crime and detection of criminals. Currently all over India $92 \%$ of the police stations are connected through this network. Despite having centralised data base of crime, criminal information along with criminal images and fingerprints with advanced search capabilities, fingerprint of unclaimed bodies find no place in the data base.

\section{Future solution- use of finger prints through authorised STQC $^{6}$ Certified electronic device linked to Aadhar number for identification of unidentified dead persons}

Aadhaar is essentially a paperless online anytimeanywhere identity assigned to a resident to cover his/her entire lifetime. The verification of the identity is done online with the help of authentication devices which connect to UIDAI's Central Identity Repository and return only a 'yes' or 'no' response to the basic query"Is the person who he/she claims to be?" based on the data available with UIDAI. The Aadhaar authentication service is fully functional and in use in several service delivery schemes across the country.STQC (Standardization Testing and Quality Certification) directorate under ministry of Electronics and Information Technology, Govt of India provides confidence that certified devices are reliable, safe, and secure and meets the requirements.

Aadhar based STQC Certified finger print scanners are now a day commonly used by the private network service provider companies for biometric verification. Presently Aadhar based identification has been occasionally used by police for identification of missing/ abandoned children ${ }^{7}$. Such devices may be made available at hospital mortuary/police chowki for identification of unclaimed dead person. Such kind of arrangement would be advantageous in following ways.

1. It is quick, easy and handy to scan the fingerprints of the unclaimed person/dead body which is brought to hospital for treatment or autopsy.

2. The record is reproducible and permanent.

3. As of now multiple agencies are involved in manual work like police taking statements, photographs, networking with different agencies like finger print bureau, newspaper agencies, NGO and mortuary for preservation of dead body in cold storage, maalkhana for preservation of belongings/biological evidence for future identification. Moreover states police are already overburdened and mostly under staffed which find less time and surprisingly less interest in investigation of unclaimed dead bodies. Disposal of unclaimed dead bodies also pose lots of other challenges for police personnel like instant payment issues related to transportation and handling of the bodies. An instant lead may be available with the help of finger print scanner at hospital side.

4. Financial expenditure and man hours on unfruitful efforts on the above said efforts could have been avoided.

5. Fingerprint based Aadhar authentication, if available would be more reliable rather than manual verification based on visual effects. Sometimes visual effects of the face may be distorted due to post-mortem artefacts/ decomposition/ injuries.

\section{Conclusion}

Identification of the unidentified dead body serves multiple purposes. Information technology based solutions like "Aadhar base STQC Certified finger print scanners" may be used in the hospitals as a suitable replacement for traditional ways of identification which are more labour intensive and time consuming. A known person becoming unidentified after death, poses a serious question to the administrators of $21^{\text {st }}$ century when we are riding in an era of e-governance.

\section{References}

1. [Internet] Available from URL; http://indianexpress.com/article/india/aadhaar-coversover-89-population-mos-kj-alphons-5089431/[Accessed on 17-05-2018].

2. Revised Standing Order [Internet] Available from: URL: http://nlrd.org/wp-content / uploads /2012/01/MISSINGPERSONS-STANDING-ORDER-DELHI-POLICE-NO252.pdf.[Accessed on 17-05-2018].

3. ZIPNET [Internet] Available from URL; http: // zipnet.in / index.php ? page $=$ un_identified_dead_bodies . [Accessed on 17-05-2018].

4. Fingerprint Analysis and Criminals Tracking System. [Internet] Available from URL http://164.100.44.112:8888/facts.aspx [Accessed on 1705-2018].

5. Crime and Criminal Tracking Network \& System. [Internet] Available from URL: http:// www. Ncrb.gov.in/ Bureau Divisions / CCTNS/ cctns.htm [Accessed on 1705-2018].

6. Standardization Testing and Quality Certification. [Internet] Available from URL: http:// www. STQC.gov.in. [Accessed on 17-05-2018].

7. [Internet] Available from URL: http:// www. Google.co.in/amp/ indianexpress.com / article / india/about-500-missing-children-traced-through-aadharuidai-4952719/ lite/. [Accessed on 17-05-2018]. 